\title{
SURAU MELALUI BAHASA TUBUH DALAM FILM EKSPERIMENTAL
}

\author{
Deddy Desmal \\ ISI Padang Panjang, deddydesmal5@gmail.com
}

\begin{tabular}{|c|c|c|}
\hline Diterima: 25 Desember 2017 & Direvisi: 4 April 2018 & Diterbitkan: 30 Juni 2018 \\
\hline
\end{tabular}

\begin{abstract}
Minangkabau has a surau as a creative container for its people to worship, study, play, exchange ideas and share experiences in ancient times. The existence of the surau is the biggest scourge of Islamic civilization in Minangkabau. Surau became the medium of educational activity of Muslims and the place of all social activities in Minangkabau. Humans communicate with other humans using direct communication (dialogue) and indirect communication (body language). Body language in general is nonverbal message communication (without words). Body language becomes an alternative way to communicate using body language or sign language. Experimental films are abstract and not easy to understand. This is because the filmmaker uses personal symbols in bis speech. Structures in experimental films by subjective interpretations of the work such as ideas, ideas, emotions and inner experiences.
\end{abstract}

Keywords: Surau, Body Language, Exprimental Film.

\begin{abstract}
Abstrak
Minangkabau memiliki surau sebagai wadah kreatif bagi masyarakatnya untuk beribadah, belajar, bermain, bertukar pikiran dan berbagi pengalaman pada zaman dabulu. Eksistensi surau menjadi momok terbesar dalam peradaban islam di Minangkabau. Surau menjadi media aktivitas pendidikan umat Islam dan tempat segala aktivitas sosial di Minangkabau. Manusia berkomunikasi dengan manusia lainnya dengan menggunakan komunikasi langsung (dialog) dan komunikasi tidak langsung (bahasa tubub). Bahasa tubuh secara umum merupakan komunikasi pesan nonverbal (tanpa katakata). Bahasa tubuh menjadi jalur alternatif untuk berkomunikasi dengan menggunakan bahasa tubuh atau bahasa isyarat. Film eksperimental berbentuk abstrak dan tidak mudah untuk dipahami. Hal ini disebabkan pengkarya menggunakan simbol-simbol personal dalam penuturannya. Struktur pada film elesperimental dipengarubi oleh interpretasi subjektif pengkarya seperti gagasan, ide, emosi serta pengalaman batin.
\end{abstract}

Kata Kunci: Surau, Bahasa Tubuh, Film Eksperimental.

\section{PENDAHULUAN}

Minangkabau memiliki objek-objek kebudayaan yang sekarang keberadaanya sudah mulai dilupakan oleh masyarakatnya sendiri, salah satunya Surau. Kata Surau merupakan istilah Melayu - Indonesia Surau dan kontraksinya Suro yang digunakan di Asia Tenggara. Kata ini banyak digunakan di Minangkabau, Sumatera Selatan, Semenanjung Malaysia, Sumatera Tengah, dan
Patani (Thailand). Surau merupakan peninggalan kebudayaan masyarakat Minangkabau sebelum datangnya Islam. ${ }^{1}$

Surau memiliki karakter yang kuat untuk membentuk masyarakat Minangkabau. Azyumardi

1 Saharman Saharman, "SURAU SEBAGAI LEMBAGA PENDIDIKAN ISLAM DI MINANGKABAU," Pendidikan Islam 1, no. 2 (September 19, 2017): 53-75. 
Azra mengatakan, "Surau adalah kepunyaan kaum, surau didirikan sebagai pelengkap Rumah Gadang yang berfungsi sebagai tempat bertemu, berkumpul, dan tempat tidur laki-laki yang telah akil baligh dan orang tua yang telah uzur". Fungsi ini berkaitan erat dengan ketentuan adat, bahwa anak laki-laki tidak mempunyai kamar di Rumah Gadang, di rumah orang tuanya sendiri. Setelah masuknya Islam, surau mengalami proses islamisasi walaupun tetap menjadi penginapan anak-anak bujang. ${ }^{2}$

Sebutan surau dikonotasikan dengan istilah langgar atau mushalla. Meskipun secara substantif tidak sepenuhnya disamakan begitu saja. Surau muncul jauh sebelum langgar atau mushalla berdiri, dan istilah surau itu merupakan warisan dari agama Hindu-Budha atau para leluhur mereka yang menganut animisme, dinamisme ataupun politeisme. Langgar biasanya digunakan untuk shalat dan mengaji bagi kaum muslim di Jawa. Kemudian para jama'ah melanjutkan dengan membaca Alquran bersama yang dipimpin oleh seorang imam yang ditunjuk sebagai pendidik di surau. Sedangkan istilah mushalla, merupakan pengembangan mutakhir yang masih sangat baru. ${ }^{3}$

Pengkarya memiliki ketertarikan terhadap perubahan budaya adat Minangkabau terhadap surau. Pengkarya melihat adanya perubahan terhadap kehidupan surau pada zaman dahulu dengan surau zaman sekarang. Lingkungan dan suasana surau sangat begitu indah bagi anak lakilaki yang telah baligh, namun pengkarya tidak menemukan hal tersebut pada saat pengkarya masih kecil. Hal tersebut dikarenakan orang tua pengkarya menginginkan anaknya untuk bermain dan tidur di

2 Mhd Natsir, "Peranan Surau Sebagai Lembaga Pendidikan Islam Tradisional Di Padang Pariaman Sumatera Barat (Surau Syaikh Burhanuddin)," Pedagogi: Jurnal Ilmu Pendidikan 12, no. 2 (November 30, 2012): 39-46.

3 Saeful Anam, "Karakteristik Dan Sistem Pendidikan Islam: Mengenal Sejarah Pesantren, Surau Dan Meunasah Di Indonesia," JALIE; Journal of Applied Linguistics and Islamic Education 1, no. 1 (March 3, 2017): 146-67, https://doi.org/10.33754/jalie.v1i1.52. rumah. Oleh sebab itu, pengkarya merasa iri dengan teman-teman yang seumuran dan merindukan suasana indah berada di surau.

Perubahan kebudayaan terjadi karena adanya ketidaksesuaian diantara unsur-unsur kebudayaan yang saling berbeda, sehingga terjadilah keadaan yang tidak sesuai dengan fungsinya bagi kehidupan. Sjafri Sairin, (2002:27) mengatakan, "Minangkabau sebagai masyarakat yang terbuka, menyadari bahwa masyarakat dan kebudayaan itu akan berubah. Pepatah Minangkabau yang berbunyi "sakali aia gadang sakali tapian baralih", ini merupakan refleksi dari kesadaran akan perubahan tersebut. Hal ini yang menyebabkan orang Minangkabau memandang perubahan sebagai suatu kewajaran". ${ }^{4}$

Mencermati sebuah perubahan kebudayaan di Minangkabau, bahwa Surau menjadi objek dalam mengungkapkan rasa dalam berkarya melalui interpretasi. Nooryan Bahari (2008:12) mengatakan, "Interpretasi adalah menafsirkan hal-hal yang terdapat dibalik sebuah karya, dan menafsirkan makna, pesan, atau nilai yang dikandungnya. Penafsiran merupakan salah satu cara untuk menjernihkan pesan, makna, dan nilai yang terkandung dalam sebuah karya, dengan cara mengungkapkan setiap detail proses interpretasi dengan bahasa yang tepat”. Setiap karya seni membutuhkan penafsiran yang tepat untuk menghasilkan penilaian yang baik. Penafsiran tersebut berasal dari gagasan yang menjadikan hal tersebut menjadi sebuah konsep dalam berkarya. ${ }^{5}$

4 Fitri Eriyanti, "ASPEK SOSIO-BUDAYA, KEBIJAKAN PEMERINTAH, DAN MENTALITAS YANG BERPENGARUH TERHADAP INTEGRASI SOSIAL DALAM MASYARAKAT SUMATERA BARAT," Humanus 12, no. 1 (June 28, 2013): 73-82-82, https://doi.org/10.24036/jh.v12i1.3106.

5 S. Suharto, "Refleksi Teori Kritik Seni Holistik: Sebuah Pendekatan Alternatif Dalam Penelitian Kualitatif Bagi Mahasiswa Seni (Reflection on Art Criticism and Holistic Art Criticism: An Alternative Approach of Qualitative Research for Art Students)," Harmonia: Journal of Arts Research 
Pengkarya menginterpretasi objek dengan pola pengungkapan bahasa tubuh. Liliweri Alo (1994:11) mengatakan sebagai berikut,

"Bahasa tubuh merupakan komunikasi pesan non verbal atau isyarat. Bahasa tubuh merupakan proses pertukaran pikiran dan gagasan di mana pesan yang disampaikan dapat berupa isyarat, ekspresi wajah, pandangan mata, sentuhan, artifak, diam, waktu, suara serta postur dan gerakan tubuh. Bahasa tubuh dapat mengirimkan informasi kepada penerima informasi (komunikan) bahwa dengan menggunakan bahagian tubuh manusia tanpa melafazkan langsung informasi yang akan disampaikan, komunikan dapat memahami informasi yang ingin disampaikan oleh pengirim informasi (komunikator)."

Keseluruhan pengungkapan rasa terhadap interpretasi pengkarya terhadap Surau, diaplikasikan ke dalam bentuk media film yaitu Film Eksperimental. Gatot prakosa (1997:75) mengatakan, "Film Eksperimental merupakan "kesatuan bentuk" sebuah film yang mengandung nilai alternatif yang berpijak pada penentuan bentuk isi serta format dari suatu jenis film". Himawan prasista (2008:8) mengatakan, "Film Eksperimental berbeda dengan dua jenis film lainnya yang tidak memiliki plot, namun tetap memiliki struktur yang jelas. Plot merupakan rangkaian peristiwa yang disajikan secara visual maupun audio dalam film". Film eksperimental tidak selalu bercerita tentang hal apapun, karena film eksperimental bercerita tentang ekspresi personal sineasnya. ${ }^{6}$

Struktur pada film eksperimental dipengaruhi oleh interpretasi subjektif pengkarya

\footnotetext{
and Education 8, no. 1 (2007), https://doi.org/10.15294/harmonia.v8i1.803.

6 John Fredy Barrera et al., "Experimental Multiplexing of Encrypted Movies Using a JTC Architecture," Optics Express 20, no. 4 (February 13, 2012): 3388-93, https://doi.org/10.1364/OE.20.003388.
}

seperti gagasan, ide, emosi serta pengalaman batin. Film eksperimental berbentuk abstrak dan tidak mudah untuk dipahami. Hal ini disebabkan karena pengkarya menggunakan simbol-simbol personal dalam penuturannya. Himawan Prasista (2008:16) mengatakan, "Secara singkat film eksperimental dianggap sebagai ekspresi sangat pribadi yang bersifat non komersial, dan dalam membangun kekhususannya, film Eksperimental selalu berdialog dengan medium lainnya".

\section{PEMBAHASAN}

Metode merupakan sebuah cara atau jalan yang di tempuh pengkarya dalam mentransformasikan ide dan gagasan dalam menciptakan sebuah karya seni. Menggunakan metode dalam berkarya akan mempermudah proses pengkarya dalam mewujudkan film Eksperimental dengan menginterpresentasikan Surau melalui bahasa tubuh. Seorang pengkarya seni dituntut untuk mampu memahami dan mengamati objek melalui kecerdasan dan kekuatan imajinasi yang dimiliki. Penciptaan karya Film Eksperimental ini berangkat dari peristiwa dan realitas sosial masyarakat Minangkabau yang terjadi pada saat sekarang ini. Pengkarya merasa terpanggil untuk memberikan sebuah kontribusi terhadap diri sendiri dan masyarakat, serta mengembangkan pemikiran dengan kreatif dan kritis dalam perwujudan karya film.

Kemudian perkembangan karya tersebut dikemas melalui tahapan-tahapan yang berawal dari tahap pra produksi hingga tahap paska produksi. Penciptaan film Eksperimental dengan menginterpresentasikan Surau melalui bahasa tubuh, menggunakan struktur pembangunan film yang menggunakantahapan-tahapan. Himawan Pratista (2008:44) mengatakan sebagai berikut,

Tiga tahapan dasar baku film, yaitu: bagian awal cerita (pengenalan/introduksi), bagian tengah (proses krisis dan konflik) dan bagian akhir cerita (klimaks dan anti klimaks). Ketiga 
bagian ini merupakan rangkuman dari susunan shot yang membentuk adegan (scene) hingga Sequence. Kemudian struktur film memiliki makna estetika, psikologis dan bahasa sinematografi yang lebih luas.

Pengkarya menempatkan kebebasan dalam menafsir dan menciptakan suasana sesuai dengan kebutuhan film, namun tidak terlepas dari esensi adat dan realitas sosial budaya masyarakat Minangkabau. Melengkapi unsur-unsur metode yang pengkarya gunakan, ada beberapa tahapantahapan yang pengkarya lakukan dalam menyusun sebuah metode, diantaranya;

\section{$\underline{\text { Tahap Observasi }}$}

Tahapan observasi merupakan tahapan pertama yang dilakukan oleh pengkarya sebelum mengeksekusi karya tersebut. Kemudian pengkarya melakukan tahapan perkembangan terhadap karya tersebut, bisa berupa membaca berbagai macam buku, riset lokasi, riset tekstual dan melakukan tahapan observasi mendalam terhadap objek. Kemudian tahapan lanjutan dari data observasi tersebut akan dikembangkan dalam merancang dan menkondisikan kembali dari perkembangan hasil data tersebut. Kemudian hasil data final rancangan dan konseptional sebelumnya yang nantinya akan mewujudkan sebuah tawaran dan kemasan terbaru dalam sebuah karya film Eksperimental.

Tahap observasi, pengkarya menggunakan tahapan Observasi Dokumenter. Gerzon ayawaila (2008:50) mengatakan sebagai berikut,

"Dokumenter dilakukan pada sumber data informasi, yang umumnya terdiri dari; 1) Data Tulisan: Buku, majalah, surat kabar, surat dan selebaran. 2) Data Visual: Foto, film, video, Lukisan, poster patung dan ukiran. 3) Data Suara: Bunyi-bunyian, musik dan lagu. 4) Data mengenai subjek, narasumber dan informan, dan 5) Data lokasi: Tempat kejadian atau peristiwa. Hasil riset dan observasi menjadi titik berangkat pembentukan kerangka global mengenai arah dan tujuan penuturan, serta subjek-subjek yang akan menjadi tokoh (karakter) dalam film".

\section{Tahap Eksplorasi}

Tahapan eksplorasi dibentuk dari rangka menemukan pilihan-pilihan yang tepat dalam kerangka dalam penceritaannya. Proses eksplorasi dilakukan dalam beberapa tahapan terutama berhubungan dengan proses penciptaan, diawali dengan tahapan melihat dan membaca, membayangkan, merasakan, mencari dan menemukan. Tahapan ekspolrasi juga dilakukan untuk ketercapaian aspek gambar yang dilakukan dalam berbagai frame dan menciptakan suasana. Perpaduan keindahan yang tertangkap oleh panca indra akan menuntun pengkarya dalam mengeksplor nalar sebagai topangan ide yang sistematis. Maka, inilah langkah awal dari sebuah eksplorasi diri dan nilai kemanusian sosial masyarakat Minangkabau. Gerzon Ayawaila (2008:51) mengatakan sebagai berikut,

"Tiga struktur penuturan dalam pada tahap eksplorasi: 1) Kronologis, peristiwa dituturkan secara berurutan dari awal hingga akhir. Menentukan konstruksi alur kisah tergantung pada waktu. 2) Tematis, cerita dipecah kedalam beberapa kelompok tema yang menempatkan sebab dan akibat digabungkan dalam tiap sekuens. 3) Dialektis, kekuatan dramatik yang menyuguhkan suatu tanda tanya atau masalah yang langsung diberi jawaban. Apabila ada aksi, langsung diberi reaksi”.

\section{Tahap Evaluasi}

Tahap evaluasi merupakan tahapan yang menjadi ciri dari kritik sebuah karya seni. Tahapan evaluasi juga merupakan tahapan dalam kritik untuk menentukan kualitas sebuah karya seni apabila dibandingkan dengan karya seni lainnya atau yang sejenis. Perbandingan dilakukan terhadap berbagai aspek formal dan konteks karya tersebut. 
Mengevaluasi dan menilai secara kritis dapat dilakukan dengan membicarakan karya-karya yang telah ada, kemudian menetapkan tujuan dan fungsi karya yang di telaah serta kebutuhan dari segi sudut pandang tertentu yang melatar belakanginya.

\section{Tahap Produksi}

Tahapan produksi terdiri dari tiga bagian yang lazim disebut Standard Operational Procedure (SOP). Fred Wibowo (2007:38) mengatakan bahwa SOP dalam sebuah produksi televisi dan film yaitu; Pra produksi, Produksi dan Pasca produksi. Sesuai dengan SOP tersebut, film ini akan diawali dengan tahap pra produksi, produksi kemudian pasca produksi, diantaranya:

Pra Produksi

Tahap pra produksi, pengkarya melakukan pembentukan tim kreatif yang terlibat dalam proses produksi dan pembagian job deskripsi. Penentuan tim kreatif sesuai dengan kebutuhan naskah dan kebutuhan di lapangan. Pengkarya melakukan perancangan storyboard yang akan digunakan pada produksi. Hal yang harus dilakukan pada tahap pra produksi adalah analisa dan reading terhadap naskah sebagai panduan utama. Dalam proses analisa dan reading ikut memutuskan item-item yang akan dibutuhkan di lapangan serta talent yang akan digunakan. Pada tahap pra produksi seluruh tim bekerja mempersiapkan segala sesuatu yang akan dibutuhkan pada produksi, seperti pembangunan set artistik, kostum, hunting lokasi, set peralatan, dan segala kebutuhan lain-lain yang dibutuhkan.

\section{Produksi}

Memasuki tahap produksi seluruh tim kreatif bekerja sesuai dengan job deskripsi masingmasing sesuai dengan konsep yang telah dirancang pada masa pra produksi. Tahap produksi merupakan tahapan perekaman audiovisual. Tahap ini biasanya disebut dengan tahap take. Tahapan produksi merupakan tahapan dimana film dibuat. Produksi sebuah film berawal dari mengumpulkan dan mewujudkan seluruh rancangan yang sudah dipersiapkan pada tahapan pra produksi.

Sebelum tahapan ini, pengkarya melakukan proses latihan terlebih dahulu untuk memastikan setiap detail gerakan-gerakan yang telah dilatihkan sebelumnya. Kemudian melakukan proses perekaman gambar dan audio. Perekeman gambar menggunakan tiga kamera (multi kamera) yang berperan sebagai kamera satu, kamera dua dan kamera tiga. Sementara itu perekaman audio dilakukan pada tahap produksi selesai, karena pada proses produksi hanya menggunakan musik giude untuk membantu mengekspresikan tubuh penari.

Pasca Produksi

Tahap pasca produksi merupakan tahap penyambungan gambar-gambar yang telah terekam saat produksi menjadi rangkaian shot yang menyatu membentuk sebuah scene dan sequence sehingga tercipta makna, maksud, tujuan dari cerita yang di audio visualkan.

Tahapan paska produksi dalam film juga biasa disebut dengan proses editing. Proses editing dilakukan setelah produksi selesai. Setelah proses produksi dilakukan, sang editor melakukan proses management file, dimana seluruh gambar disusun menurut kebutuhan editing. Kemudian masuk pada project editing dan menyusun gambar-gambar sesuai naskah menjadi tiga bahagian. Proses ini dinamakan dengan editing offline.

Setelah gambar selesai disusun sesuai naskah, maka proses selanjutnya yaitu pembuatan musik. Pembuatan musik dilakukan sesuai alunan dan emosi yang dihasilkan dalam susunan-susunan gambar yang telah dirancang sebelumnya. Setelah musik selesai, masuklah pada tahap editing online. Editing online merupakan proses final dalam editing; menyambung dan membentuk sebuah emosional film sesuai tuntunan naskah.

\section{PENUTUP}

Minangkabau memiliki surau sebagai wadah kreatif bagi masyarakatnya pada zaman dahulu. 
Surau dihadirkan untuk menjadi pelengkap dari rumah gadang. Peranan surau dalam kehidupan masyarakat dapat memberikan energi positif bagi pelestarinya. Surau menjadi tempat untuk menuntut ilmu bagi anak bujang Minangkabau. Pendidikan non formal surau pada hakikatnya menciptakan sebuah wadah kreatif dan inovatif bagi calon bujangan-bujangan Minangkabau yang hendak pergi merantau, khususnya.

Bahasa tubuh merupakan bahasa isyarat yang dilakukan dengan lawan berkomunikasi. Bahasa tubuh yang dilakukan secara sadar bisa dan mudah dimanipulasi, disesuaikan dengan apa yang di sampaikan. Sebaliknya, bahasa tubuh yang terucap tanpa disadari dapat mengungkapkan makna rahasia yang tak terlontarkan. Penyampaian pesan berupa isyarat, ekspresi wajah, pandangan mata, sentuhan, serta gerakan tubuh. Karena bahasa tubuh merupakan bahasa yang "diucapkan" oleh tubuh seseorang, bisa dilakukan secara sadar, bisa pula dilakukan tanpa disadari.

Melalui film eksperimental bahasa tubuh dapat memberikan sebuah informasi yang jamak diterima oleh penonton. Simbol-simbol yang di peragakan oleh penari dapat memberikan sebuah informasi dengan satu tujuan. Film eksperimental umumnya tidak bercerita tentang apapun bahkan kadang menentang kausalitas. Film-film eksperimental umumnya berbentuk abstrak dan tidak mudah dipahami. Hal ini disebabkan karena menggunakan simbol-simbol personal yang mereka ciptakan sendiri. Secara singkat film eksperimental dianggap sebagai ekspresi sangat pribadi dan personal dalam menggunakan medium film bersifat non-komersial, dan dalam mencari kekhususan film selalu berdialog dengan medium lainnya.

Menyampaikan dan memberikan sebuah informasi melalui sebuah film, yakni sangat sulit untuk diungkapkan. Film dokumenter dan film fiksi termasuk dua jenis film yang lebih transparan untuk menyampaikan sebuah informasi kepada penonton. Film eksperimental memiliki struktur caerita yang sangat sulit untuk dipahami. Menyampaikan informasi melalui film eksperimental dengan bahasa insyarat dan menggunakan simbol-simbol tidak langsung merupakan gaya bertutur film eksperimental.

Keterbatasan pengkarya terhadap waktu dalam mengupas dan menggali lebih dalam mengenai konten dari surau, itu sangat menguras pemikiran. Butuh pemahaman dan pengetahuan yang tingi untuk dapat merampung semua sejarah ini. Semua data dan informasi yang dihadirkan dalam tulisan ini belum sempurna dan masih banyak revisi untuk pendalaman materi.

Kemudian penciptaan sebuah karya film degan menggunakan bahasa tubuh tanpa dialog dan adegan untuk menyampaikan sebuah informasi, memberikan pengalaman baru terhadap pengkarya. Pengkarya banyak menemukan hal-hal baru dalam berkarya, sehingga maksud dan tujuan yang dikehendaki dalam film ini bisa tersampaikan kepada penonton. Setelah pesan dalam film ini dapat tersalurkan kepada masyarakat, setidaknya hal tersebut menjadi tolak ukur bagi masyarakat untuk menjadi kehidupan yang lebih baik.

\section{DAFTAR KEPUSTAKAAN}

Anam, Saeful. "Karakteristik Dan Sistem Pendidikan Islam: Mengenal Sejarah Pesantren, Surau Dan Meunasah Di Indonesia." JALIE; Journal of Applied Linguistics and Islamic Education 1, no. 1 (March 3, 2017): 146-67. https://doi.org/10.33754/jalie.v1i1.52.

Barrera, John Fredy, Myrian Tebaldi, Carlos Ríos, Edgar Rueda, Néstor Bolognini, and Roberto Torroba. "Experimental Multiplexing of Encrypted Movies Using a JTC Architecture." Optics Express 20, no. 4 (February 13, 2012): 3388-93. https://doi.org/10.1364/OE.20.003388.

Eriyanti, Fitri. "ASPEK SOSIO-BUDAYA, KEBIJAKAN PEMERINTAH, DAN MENTALITAS YANG BERPENGARUH TERHADAP INTEGRASI SOSIAL 
DALAM MASYARAKAT SUMATERA BARAT." Humanus 12, no. 1 (June 28, 2013): 73-82-82. https://doi.org/10.24036/jh.v12i1.3106.

Natsir, Mhd. "Peranan Surau Sebagai Lembaga Pendidikan Islam Tradisional Di Padang Pariaman Sumatera Barat (Surau Syaikh Burhanuddin)." Pedagogi: Jurnal Ilmu Pendidikan 12, no. 2 (November 30, 2012): 39-46.

Saharman, Saharman. "SURAU SEBAGAI LEMBAGA PENDIDIKAN ISLAM DI MINANGKABAU." Pendidikan Islam 1, no. 2 (September 19, 2017): 53-75.

Suharto, S. "Refleksi Teori Kritik Seni Holistik: Sebuah Pendekatan Alternatif Dalam Penelitian Kualitatif Bagi Mahasiswa Seni (Reflection on Art Criticism and Holistic Art Criticism : An Alternative Approach of Qualitative Research for Art Students)." Harmonia: Journal of Arts Research and Education 8, no. 1 (2007). https://doi.org/10.15294/harmonia.v8i1.8 03. 